\title{
Sexually Transmitted Infections in the Elderly: Systematic Review
}

\author{
Mayara Maria Souza de Almeida* \\ Faculty of Nursing, Federal University of Goiás, Brazil \\ *Corresponding author: Mayara Maria Souza de Almeida, Nurse, Doctorate student Federal University of Goiás, Professor University of São Paulo, \\ Goiânia, Goiás, Brazil
}

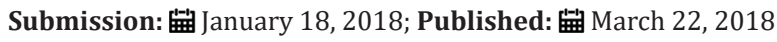

\section{Introduction}

It is believed that the increase in life expectancy in the last decades has led to a change in the global age profile. The magnitude of people aged 60 and over is increasingly growing, compared to any other age group in the world [1]. However, the expectancy for the future is very different, because it is expected that, in 40 years, $22 \%$ of the total population will be at least 60 years old, expanding from 800 million to 2 billion people. In Brazil [2], there are approximately 20 million people aged 60 or over, which represents about $10 \%$ of the entire population, with an estimation of 32 million elderly people in 2025 [3]. In the context of sexuality, researchers have indicated that elderly people remain sexually active, even after 80 years old. However, unsafe sexual practices contribute to a greater vulnerability of this population to the Human Immunodeficiency Virus (HIV) and other Sexually Transmitted Infections (STIs), such as syphilis, chlamydia and gonorrhoea [2].

\section{HIV in the Elderly}

According to data from the World Health Organization (WHO) and UNAIDS (Joint United Nations Program on HIV/AIDS), about 40 million people in the world live with HIV/AIDS and, among those, 2,8 million are 50 years old or over [4]. In the United Kingdom, the incidence doubled from 1996 to 2003, with 11\% of cases of AIDS being diagnosed in people aged 50 or over. In the United States, only 7,5\% of diagnoses of AIDS in 1982 were relative to people over 50 years old. However, in 2006 this population represented 15,5\% of new HIV diagnoses, totalizing $25 \%$ of people living with HIV, $20,5 \%$ of diagnoses of AIDS, $32 \%$ of people living with AIDS and $39 \%$ of all deaths caused by HIV/AIDS. In Australia, the National Notifiable Diseases Surveillance System showed that, from a total of 30.486 cases diagnosed as HIV infection until 2011, 10\% were relative to people aged 50 or over. In Brazil, nevertheless, HIV infection is of compulsory notification, which is believed to lead to more conclusive data [5]. According to the Ministry of Health, there was a $41 \%$ increase in its incidence among the 50-59 year age group from 1998 to 2010, moving from 15,6 to 22,1 cases per 100.000 inhabitants. In the 60 -plus age group, the increase reached $42,8 \%$ in the same period, making the incidence rate vary from 4,9 to 7 cases per 100.000 inhabitants6. From 1980 to June 2012, there were 656.701 cases of AIDS notified in the general population, and 18.712 cases in people aged 60 or over [6].

\section{Risk Factors for Transmitted Infections (STIs)}

HIV can also be contracted through contact with contaminated blood (blood transfusion and sharing needles and syringes), during pregnancy and breast-feeding. This means that the main risk factor for STIs in the elderly is unsafe sex. As age increases, there is a certain disposition to reduce the use of preservatives in sexual relations. It is believed that this increase of HIV cases in the elderly is associated with factors such as: less worry about conception $[2,5,7,8]$, difficulties handling the preservative and a worse sexual performance $[5,7,8]$; failure of elderly women in negotiating the use of preservative, relationship stability, submission to the partner $[5,7]$ and use of medication to treat erectile dysfunction [5].

\section{Conclusion}

Considering the facts presented here, it is necessary to develop interventions towards prevention and early diagnose of sexually transmitted infections (STIs) in the elderly population, aiming to decrease the incidence and prognosis related to cases of AIDS. Such interventions and care must be, mainly, related to prevention methods, such as the importance of using a preservative during sexual relations, as well as how to use it-considering that several researches $[5,7,8]$ identified a lack of knowledge on how to use a preservative. Therefore, it is very important to capacitate the multi professional team and promote constant debates about the theme with the community, which can happen through conversation circles, informal chats, and consultations-both individual and collective (with the partner)-in order to clarify and orient this population.

\section{References}

1. Sousa KA, Freitas FFQ Castro AP, Oliveira CDB, Almeida AAB, et al. (2017) Prevalence of depression symptoms in elderly people assisted by the Family Health strategy. REME-Rev Min Enferm 21: e-1018.

2. Andrade J, Ayres JA, Alencar RA, Duarte MT C, Parada CMGL (2017) Vulnerability of the elderly to sexually transmitted infections. Actapaul. Enferm 30(1): 8-15. 
3. Ministério da Saúde (2010) Secretaria de Atenção à Saúde. Departamento de Ações Programáticas e Estratégicas. Atenção à saúde da pessoa idosa e envelhecimento. Ministério da Saúde, Brasília, Brazil.

4. Brasil Ministério da Saúde (2011) Secretaria de Vigilância em Saúde. Department of STD, AIDS and Viral Hepatitis. AIDS-STD Epidemiological Bulletin, Brasília, Brazil.

5. Dornelas NJ, Nakamura AS, Cortez LER, Yamaguchi MU (2015) Sexually transmitted diseases in the elderly: a systematic review. Cien Saude Colet 20(12): 3853-3864
6. Brasil Ministério da Saúde (2011) Secretaria de Vigilância em Saúde. Departamento de DST, AIDS e Hepatites Virais. Boletim Epidemiológico AIDS-DST, Brasília, Brazil.

7. Madeira K, Simões PWTA, Heluany MCV, Heluany CCV, Mello MCS (2014) The knowledge of HIV/AIDS by a group of elderly people at Criciúma-SC/Brazil. Geriatr Gerontol Aging 8(1): 43-49.

8. Viana PÁ da Silva, Novais CT, Reis RWC, Flor SMC, Rosa PB (2017) Epidemiological, clinical, and evolutionary aspects of aids in the elderly in Northern Ceará. SANARE Sobral 16(2): 31-36.

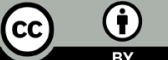

Creative Commons Attribution 4.0 International License

For possible submissions Click Here
Submit Article

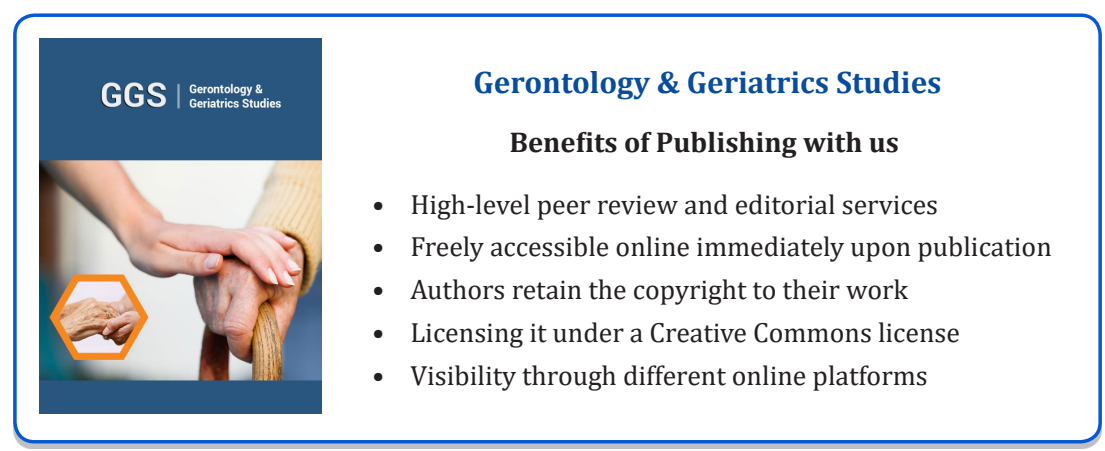

